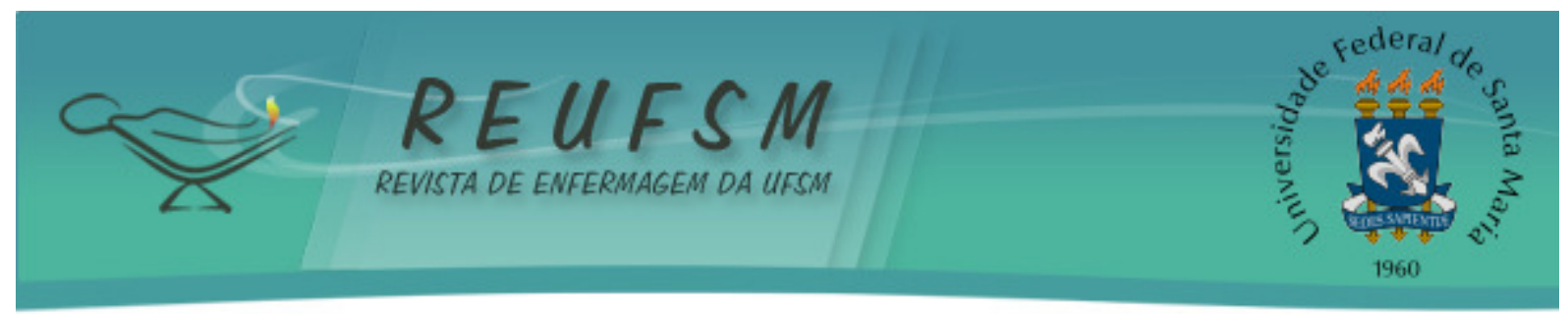

ARTIGO ORIGINAL

\title{
CRIANÇAS E O CONHECIMENTO DE SI PRÓPRIAS A PARTIR DE HISTÓRIAS INFANTIS
} CHILDREN AND THE SELF-KNOWLEDGE ACQUIRED FROM CHILDREN'S STORIES

\section{LOS NIÑOS Y EL CONOCIMIENTO QUE TIENEN DE SÍ MISMAS A TRAVÉS DE HISTORIAS INFANTILES}

Doi: $10.5902 / 2179769214678$

Gimene Cardozo Braga ${ }^{1}$

Luciane Prado Kantorski ${ }^{2}$

Valéria Cristina Christello Coimbra ${ }^{3}$ Janaína Quinzen Willrich ${ }^{4}$

RESUMO: Objetivo: verificar o conhecimento que as crianças têm de si próprias através da contação de histórias infantis com temas específicos para a saúde. Método: pesquisa qualitativa exploratório-descritiva que utilizou como instrumento histórias infantis com temas sobre transtornos: depressão infantil, déficit de atenção e hiperatividade. Foram realizados dois encontros num serviço de saúde mental infantil com crianças entre 6 e 10 anos. Utilizou-se o método de contação de histórias e a técnica de grupo operativo. Resultados: as histórias mostraram-se como mediadores capazes de auxiliar a enfermagem na escuta da vida das crianças e seus afetos. O conhecimento que as crianças têm de si próprias mostrou-se a partir de identificações de seus sentimentos com os das personagens e nas dificuldades de relacionamento e de aprendizagem. Considerações finais: essas histórias possibilitaram educar em saúde, assim como promover a saúde mental, por meio da manifestação da identificação-projeção infantil.

Descritores: Enfermagem; Saúde mental; Jogos e brinquedos.

ABSTRACT: Aim: to verify the self-knowledge children acquire by storytelling on specific children health themes. Method: it is a descriptive-exploratory qualitative study that utilized as instruments children's stories with themes about disorders: childhood depression, attention deficit and hyperactivity disorder. Two meetings were held in a child mental health service, with children between 6 and 10 years old. It was used the method of storytelling and the technique of the operative group. Results: the stories appeared as mediators able to assist nursing by listening to the children's lives and affection. Children's self-knowledge was shown by identification of their own feelings with the characters' feelings besides the difficulties in relationships and learning. Final remarks: those stories enabled teaching on health, as well as to promote mental health through the child identification-projection manifestation.

Descriptors: Nursing; Mental health; Play and playthings.

\footnotetext{
${ }^{1}$ Enfermeira. Mestre em Ciências pelo Programa de Pós-Graduação em Enfermagem da Universidade Federal de Pelotas. Docente do Curso de Graduação de Enfermagem do Instituto Federal do Paraná - Campus Palmas, Palmas, Paraná, Brasil. E-mail: gimene.braga@ifpr.edu.br.

2 Enfermeira. Doutora em Enfermagem Psiquiátrica. Docente da Faculdade de Enfermagem da Universidade Federal de Pelotas, Pelotas, Rio Grande do Sul, Brasil. E-mail: kantorski@uol.com.br

${ }^{3}$ Enfermeira. Doutora em Enfermagem Psiquiátrica. Docente da Faculdade de Enfermagem da Universidade Federal de Pelotas, Pelotas, Rio Grande do Sul, Brasil. E-mail: valeriacoimbra@hotmail.com

${ }^{4}$ Enfermeira. Mestre em Ciências pelo Programa de Pós-Graduação em Enfermagem da Universidade Federal de Pelotas. Doutoranda pelo Programa de Pós-Graduação em Enfermagem da Universidade Federal de Pelotas. Docente da Faculdade de Enfermagem da Universidade Federal de Pelotas, Pelotas, Rio Grande do Sul, Brasil. E-mail: janainaqwill@yahoo.com.br
} 


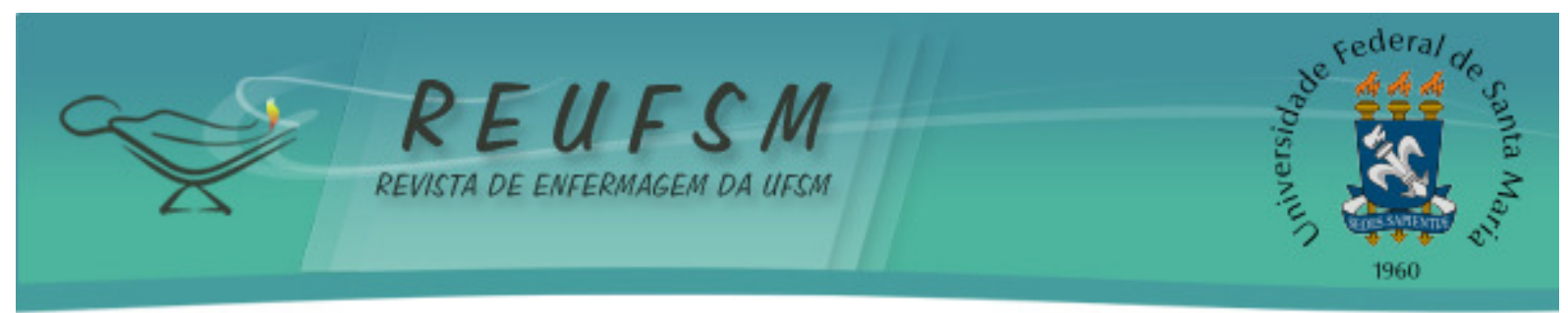

RESUMEN: Objetivo: examinar el conocimiento que los niños tienen de sí a través de historias específicas de la salud. Método: investigación cualitativa exploratoriadescriptiva, que utilizó como instrumentos historias infantiles sobre perturbaciones: depresión infantil, déficit de atención y hiperactividad. Se realizaron dos encuentros en un servicio de atendimiento público de salud mental infantil, con niños de entre 6 y 10 años. Se utilizó el método de narración de historias y la técnica de grupo operativo. Resultados: las historias se mostraron como mediadoras capaces de auxiliar las enfermeras en la escucha de la vida de los niños. El conocimiento que los niños tienen de sí se mostró a partir de identificaciones de sus sentimientos con el de los personajes y en las dificultades de relacionamiento y aprendizaje. Conclusiones: las historias posibilitaran educar en salud y promover la salud mental por medio de la manifestación de la identificación-proyección infantil.

Descriptores: Enfermería; Salud mental; Juego e implementos de juego.

\section{INTRODUÇÃO}

As histórias infantis, utilizadas como mediadores terapêuticos, são narrativas cujo enredo é construído e direcionado às crianças, aproximando-as das noções de tempo e espaço, emoções, personagens e mudanças. ${ }^{1}$ A relevância desse recurso consiste na capacidade de trabalhar as representações simbólicas e psíquicas, ao estimular a imaginação e auxiliar na identificação e na compreensão da criança a respeito de seu mundo externo. ${ }^{1}$ Como espaço transicional, a história conforta a criança e auxilia no enfrentamento de suas emoções complexas. ${ }^{2}$

Diferentemente dos adultos, a psicoterapia para crianças não busca a narração das memórias, destarte, utiliza-se de histórias infantis por meio de uma narrativa pronta, para encontrar uma forma de brincar e elaborar a própria história de vida. ${ }^{3}$ Por isso, as histórias infantis têm sido muito utilizadas na prática clínica psicoterápica, pois contribuem de maneira significativa na intervenção, destacando o crescente uso dos contos como instrumentos terapêuticos em oficinas na área da saúde devido a sua congruência com a vida das crianças. ${ }^{4}$

Enfermeiros utilizam histórias infantis na atenção à saúde através do brinquedo terapêutico. 0 brinquedo terapêutico é um recurso valorizado na assistência à criança, mas ainda enfrenta dificuldades e resistência de implantação. ${ }^{5-7}$ Diferentes aplicações desse são encontradas no intuito de diminuir o estresse durante a internação infantil/brincar livremente ${ }^{7-12}$; obter cooperação/facilitar o vínculo com a criança ${ }^{7-9,12}$; na recuperação da criança $^{12}$; no preparo de procedimentos invasivos hospitalares e cirúrgicos $^{5,7-9,11-14}$; para facilitar a compreensão do processo-saúde-doença/educar ${ }^{8,15}$; na coleta de dados em pesquisa ${ }^{15-17}$; na expressão dos sentimentos/comunicação eficaz $^{7-12,17}$; na promoção da saúde mental. ${ }^{17}$

Observa-se que em sua maioria os estudos de enfermagem ${ }^{5-11}$ fazem uso de fábulas e contos tradicionais para humanizar o cuidado. Todavia, a utilização de histórias elaboradas, por enfermeiras, para abordar temas específicos para a saúde, mostra-se escassa e aponta uma forma diferenciada e pouco empreendida de intervenção de enfermagem. ${ }^{15,17}$

Diante disso, esta pesquisa apresenta através da criação e utilização de histórias infantis uma forma educativa e terapêutica à intervenção de crianças com transtornos mentais em um centro de atenção psicossocial infantil.

Considera-se, ainda, a contação de histórias em espaços grupais como uma estratégia promotora de saúde mental, pois é capaz de fortalecer e pontecializar os processos saudáveis, e o empoderamento das crianças a respeito de seus sentimentos e 


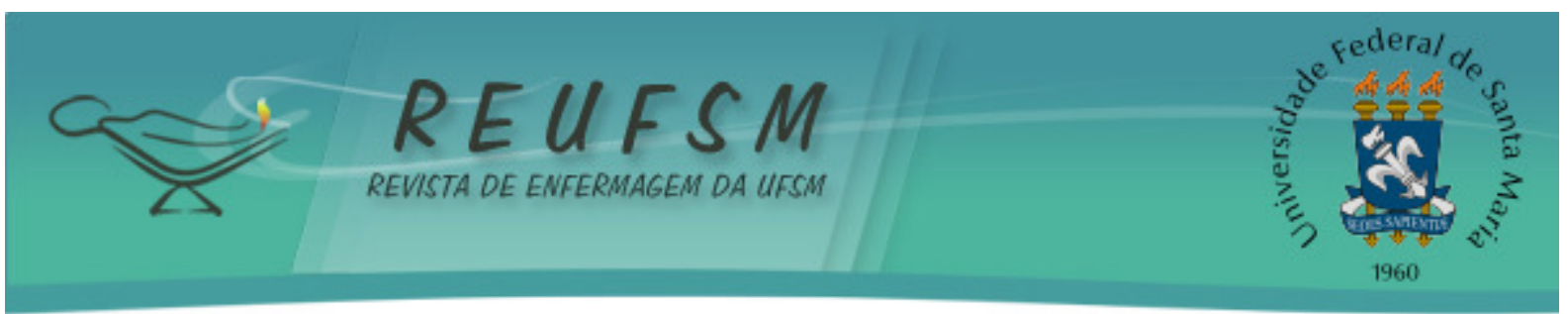

reações comportamentais. ${ }^{17}$ Dessa forma, este estudo objetivou verificar o conhecimento que as crianças têm de si próprias através da contação de histórias infantis com temas específicos para a saúde.

\section{MÉTODO}

A pesquisa caracterizou-se como descritiva-exploratória de natureza qualitativa ${ }^{18}$. Foi realizada em um Centro de Atenção Psicossocial Infantil (CAPSi), no estado do Rio Grande do Sul com quatro crianças de seis a dez anos de idade. As crianças foram escolhidas intencionalmente de acordo com os seguintes critérios de seleção: estarem em atendimento no serviço; encontrarem-se devidamente matriculadas na escola; ter o diagnóstico de Depressão ou de Déficit de Atenção/Hiperatividade. Como critério de exclusão as crianças não podiam apresentar sintomas produtivos de psicose no momento da pesquisa; e nem possuir déficit cognitivo ou retardo mental grave. Os critérios diagnósticos e resultados de testes psicológicos foram adquiridos no prontuário das crianças no CAPSi.

A coleta de dados deu-se por meio do grupo operativo o qual se centra na tarefa, entendido como capaz de produzir outras formas de enfrentamento e resolução dos problemas. $^{19}$

Foram dois encontros no mês de julho de 2007, com duração de uma hora e meia cada. Os dados foram registrados em um gravador de áudio, e em diários de campo produzidos por um segundo observador (enfermeira do serviço) e pela pesquisadora de campo.

Histórias infantis foram criadas pela pesquisadora como disparadoras dos temas: a depressão infantil ( 0 Menino Triste) ${ }^{20}$ e o déficit de atenção e hiperatividade (Lili a boneca de corda) ${ }^{21}$. Cada encontro trabalhou uma das histórias por vez e utilizou outra duas atividades: desenhos e a reconstrução da história, como mostra o Quadro 1.

\begin{tabular}{|l|l|l|l|l|}
\hline Encontros & Histórias & $\begin{array}{l}\text { Instrumentos } \\
\text { Adicionais }\end{array}$ & \multicolumn{2}{|l|}{ Atividades } \\
\hline $1^{\circ}$ & O Menino triste & Dedoches* & Desenhos da história & $\begin{array}{l}\text { Reconstrução da } \\
\text { história pela } \\
\text { criança }\end{array}$ \\
\hline $2^{\circ}$ & $\begin{array}{l}\text { Lili a boneca de } \\
\text { corda }\end{array}$ & Bonecos & $\begin{array}{l}\text { Reconstrução da história } \\
\text { pela criança }\end{array}$ & $\begin{array}{l}\text { Desenhos da } \\
\text { história }\end{array}$ \\
\hline
\end{tabular}

Quadro 1 - Disposição dos encontros. Pelotas, RS, Jul. 2007.

* Pequenos fantoches para serem utilizados nos dedos das mãos.

O desenho da história e a reconstrução da narrativa foram utilizadas ao término da contação da história para verificar as relações estabelecidas entre a história e as identificações das crianças. ${ }^{22}$

0 tratamento dos dados seguiram os passos da análise de conteúdo temática. ${ }^{18}$ Durante a pré-análise, o material foi organizado e classificado. Os dados dos diários, registros em áudio e desenhos foram agrupados e organizados em categorias operacionais. As crianças foram identificadas por nomes de cores: Laranja (9 anos), Amarelo (10 anos), Azul ( 8 anos) e Verde (6 anos). As gravações transcritas foram identificadas como encontros 1 e 2 (E1 e E2).

$\mathrm{Na}$ fase de exploração do material e de interpretação os dados referentes aos diferentes instrumentos (diário de campo, gravações e desenhos) foram aproximados a fim de se estabelecer relações entre eles e organizar as categorias que deram origem às temáticas do estudo. Este artigo apresentará apenas os dados referentes à análise da 


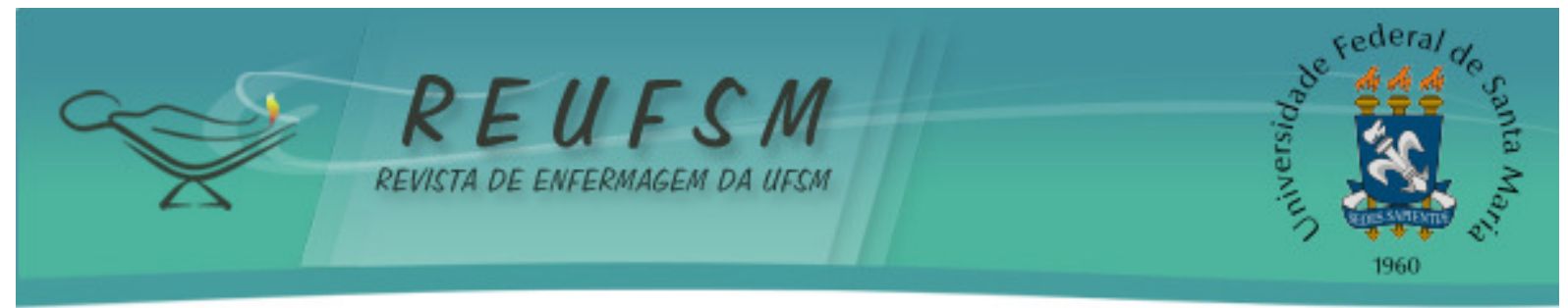

contação das histórias e da reconstrução destas pelas crianças oriundas das gravações e dos diários de campo.

As histórias utilizadas na pesquisa foram revisadas por uma equipe técnica (psicopedagoga, psicóloga e pedagoga) e a participação das crianças no estudo foi autorizada por seus responsáveis por meio da assinatura do Termo de Consentimento Livre e Esclarecido, e pelas próprias crianças verbalmente, respeitando a Resolução n ${ }^{\circ}$ 196/96 do Conselho Nacional de Saúde ${ }^{23}$. A pesquisa foi autorizada pelo Comitê de Ética da Faculdade de Medicina da Universidade Federal de Pelotas, em junho de 2007 sob ofício $\mathrm{n}^{\circ} 069 / 07$.

\section{RESULTADOS E DISCUSSÃO}

\section{A contação de histórias e as identificações infantis}

Ao abordar a história 0 menino triste durante a contação, as identificações infantis tornaram-se visíveis. Evidenciaram-se os meninos que possuem diagnóstico de depressão, Amarelo e Azul. A cada nova frase narrada, o menino Amarelo mostrava-se mais familiarizado à história, chegando a um momento em que o sentimento do personagem refletia o seu.

[Rafael logo resmungou: _Não preciso de amigos, não preciso de ninguém!].

Eu não preciso de amigos também. Ah, eu tenho saúde mental, então. Eu tenho atendimento duas vezes na semana com a [nome de psicóloga do serviço]. (Amarelo)

Destaca-se que tanto a identificação projetiva quanto a introjetiva originam-se da experiência do ser, da forma de relacionar-se com esse sentimento, pois traz a ideia de estar-em-união. ${ }^{2}$ Essas identificações foram evidenciadas, neste estudo, por meio dos movimentos corporais de ambos os meninos, Azul e Amarelo, que demonstravam inquietação e participações espontâneas ainda durante a narração da história. Comportamentos semelhantes a esses, introjetivos e projetivos, evidenciaram-se em outros estudos como positivo às crianças. ${ }^{14-17}$

[Azul e Amarelo levantaram seus troncos em direção à pesquisadora].

Eu tenho depressão. (Amarelo)

Eu tenho depressão. Eu tenho depressão. (Azul)

A história Lili a boneca de corda é mais longa que a primeira. Azul e Laranja não demonstraram nenhuma dificuldade com relação à história. Quando a narrativa falou sobre a agitação de Lili, Verde começou a simular gritos baixinho, encenando a mesma agitação, com uma das bonecas em mãos.

[Lili começou a falar e não parava mais, começou a mexer-se de um lado para o outro como se não tivesse controle de si].

[...] aaaaaahhhh, uuuuuaaaaaaahhhhh. (Verde)

[Vocês estão preocupados com a Lili?].

Não! (Verde)

Verde utilizou-se do brincar, paralelo à história contada, que confere um processo evolucional do plano afetivo da criança, pois se admite que o ato de brincar não significa 


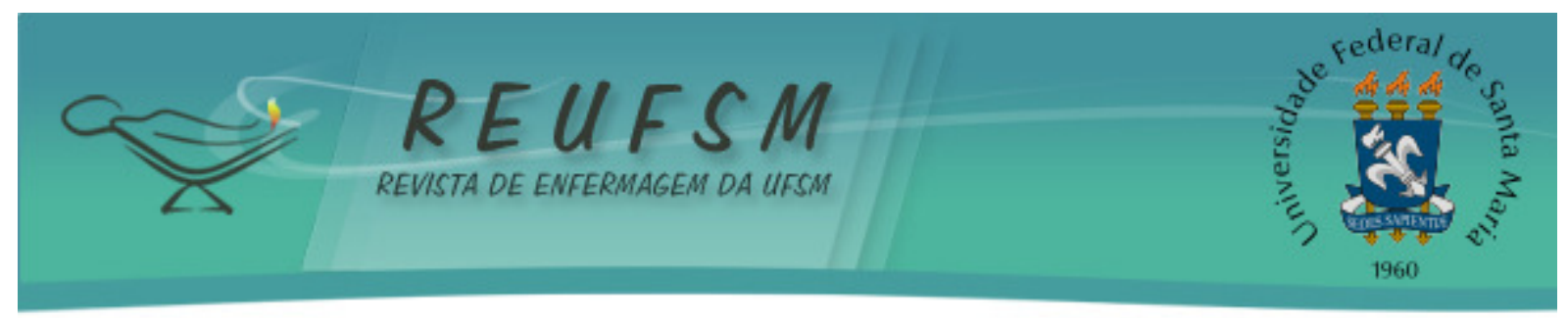

não escutar, consistindo na apropriação da palavra do contador de histórias. Esse comportamento é positivo e reflete segurança e alívio. Assim, Verde pôde afastar-se do grupo, sem que isso o fizesse sentir-se sozinho. ${ }^{1-2}$

Verde identificou-se com a agitação da personagem e acompanhou a narrativa inquieto, e Azul estava visivelmente contrariado com a situação, e verbalizou não querer mais que a contação continuasse. Nesse momento, evidencia-se um processo grupal de resistência à mudança, medo de descobrir coisas que até então se encontram intrapsíquicas, bem como medo de novos sintomas que estavam imperceptíveis ao sujeito. 0 medo faz com que o sujeito fixe-se ao significado de si, já conhecido, que confere segurança. 0 medo do ataque, ou o medo de curar-se, refere-se à concepção já conhecida de adoecimento, geradora de ansiedade. ${ }^{19}$

Considera-se que a utilização do lúdico vantajosa, direta ou indiretamente, durante a coleta de dados em pesquisa com crianças. ${ }^{12,16}$

Os recursos adicionais utilizados, no primeiro encontro, os dedoches, provocou curiosidade. As crianças espiavam, mexiam, mas como a pesquisadora utilizou-os em suas mãos durante a contação, elas só interagiram com os dedoches ao término da atividade. Ação essa modificada no segundo encontro.

Considera-se, nesse processo, a escuta da criança como um reconhecimento dessa como um agente social e participante. Sendo assim, o pesquisador deve mostrar-se flexível, auxiliando-a na expressão de suas emoções e tornando o espaço propício à negociação e à expressão para além da linguagem oral. Essa "não é central e nem única, mas fortemente acompanhada de outras expressões corporais, gestuais e faciais". 24:45

$\mathrm{Na}$ segunda história, durante o segundo encontro, os bonecos foram disponibilizados às crianças. Verde, Laranja e Azul brincaram com a boneca "Lili**", antes de iniciar a narrativa. Azul segurava o "Juju"** enquanto, a pesquisadora manipulava os outros bonecos durante a contação. Verde participou durante toda a contação da história com a Bruxa Sapeca* $^{* *}$ em suas mãos.

Destaca-se que as crianças, antes de controlarem seu comportamento, tentam controlar o ambiente por meio da fala. A fala possui uma função intrapessoal (egocêntrica), além de uso interpessoal (social). Ambas estão ligadas através de transições que ocorrem durante o desenvolvimento da criança, assim a fala torna-se um instrumento para solucionar problemas. ${ }^{24-26}$

Verde, durante a contação da história, utiliza-se mais da fala egocêntrica do que da fala social. Esse permaneceu recriando a narrativa e recontando-a paralelamente a leitura da história. Assim, os recursos visuais como os dedoches e os bonecos mostraram-se como facilitadores à projeção infantil, funcionando como objetos transicionais ${ }^{2 * * *}$, para a reconstrução do imaginário infantil e suas conexões com a realidade. Instrumentos como os dedoches e os bonecos favorecem a expressão da subjetividade infantil, maior expressão verbal da criança, além de aproximá-la do pesquisador. ${ }^{16}$

Durante o processo grupal as crianças interagiram e trabalharam com esses materiais "identificação-projeção", o que facilitou o criar e transmitiu-lhes segurança, pois o boneco propicia que a criança desloque seus sentimentos para os objetos, fazendo com que esta se sinta mais segura em demonstrar seus sentimentos íntimos. 0 brincar e a relação com o boneco são formas evidenciadas da promoção da saúde mental infantil. ${ }^{2}$

\footnotetext{
** Bonecos que representavam as personagens da história Lili a boneca de corda

*ntende-se por objeto transicional um espaço de transição pela qual a criança passa para entender algo que sua cognição ainda não permite como suas emoções mais complexas. É algo que não está dentro, intrapsíquico, e nem fora, como os conteúdos da realidade externa.
} 


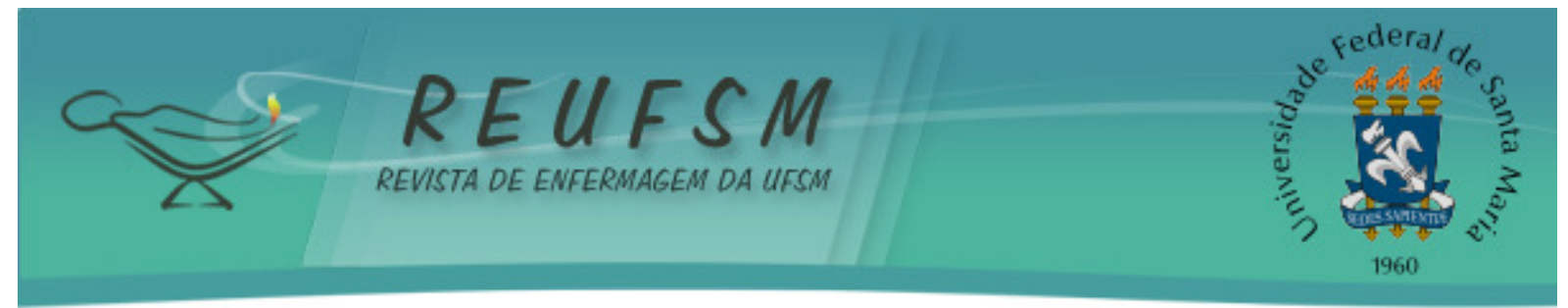

Verifica-se que a criança utiliza o boneco como um meio concreto/palpável de contar a sua história, tornando-se capaz de expressar o que the é difícil dizer., ${ }^{2,22}$

Portanto, através da brincadeira com os bonecos e os dedoches, as crianças realizaram o manejo de suas fantasias e domínio de suas ansiedades de maneira a elaborar e reorganizar seu mundo interno.

\section{(Re)contando histórias como forma de se (re)conhecer}

$\mathrm{Na}$ atividade de reconstrução das histórias, o grupo apresentou-se diferente nos dois encontros. No primeiro dia, Azul iniciou sua narrativa com insegurança. Referia não se lembrar da história, falava baixo, segurando os dedoches nas mãos:

Esse daqui é o doutor dele. E aqui é a enfermeira dele. Tá todo mundo dançando, a mãe dele, e a doutora dele. Ele vai pro CAPS e pra escola. (Azul)

Quando terminou, Laranja solicitou os dedoches para contar sua história e com eles calçados aos dedos iniciou a contação. No entanto, foi interrompida por Azul que passou a se mostrar encorajado a falar. Ao falarem de si mesmas, as crianças expunham a relação com a escola.

E a mãe dele leva ele pro CAPS, pro colégio e só. (Laranja)

Ele tem depressão! (Azul)

[Que idade ele tem?].

Ele vai pro colégio e tira nota boa. (Azul)

[O que ele mais gosta de estudar?].

Matemática! (Azul)

[E quem o leva para o colégio?].

É a mãe dele. Ele tinha a mãe dele e a minha idade. (Azul)

Seis. (Verde)

Ele tem oito! Não é seis. (Azul)

E tem que ir pro colégio, tem que andar de skate, tem que andar de bicicleta, tem que é. (Verde)

Ele é o Rafael [personagem da história]! (Azul)

Durante a narração de 0 Menino triste parece que Azul e Amarelo precisavam de um tempo para recompor-se do contato inicial com uma narrativa tão familiar às suas vidas. Azul, mesmo não querendo reconstruir a história, interferia na narrativa das outras crianças, mostrando-se irritado quando Laranja e Verde não se lembravam dos detalhes (idade e diagnóstico da personagem). Amarelo, por sua vez, transformou a personagem principal em Ninja projetando-se na história.

A função do grupo é justamente centrar-se na resistência à mudança, promovendo sua mudança no sentido grupal (operativa), de forma que o explícito, aquilo que é manifestado no grupo, possa ser interpretado e trabalhado para que apareça uma nova descoberta ou um novo aspecto dos sintomas. ${ }^{19}$

A história possibilitou a Amarelo relatar os sentimentos vivenciados com os profissionais do serviço de atenção psicossocial e da escola. Isso corrobora, com achados de outro estudo desenvolvido com crianças institucionalizadas ${ }^{10}$, quando crianças estimuladas ludicamente com auxílio de histórias também, sentiram-se encorajadas para verbalizar a respeito de suas vivências. 


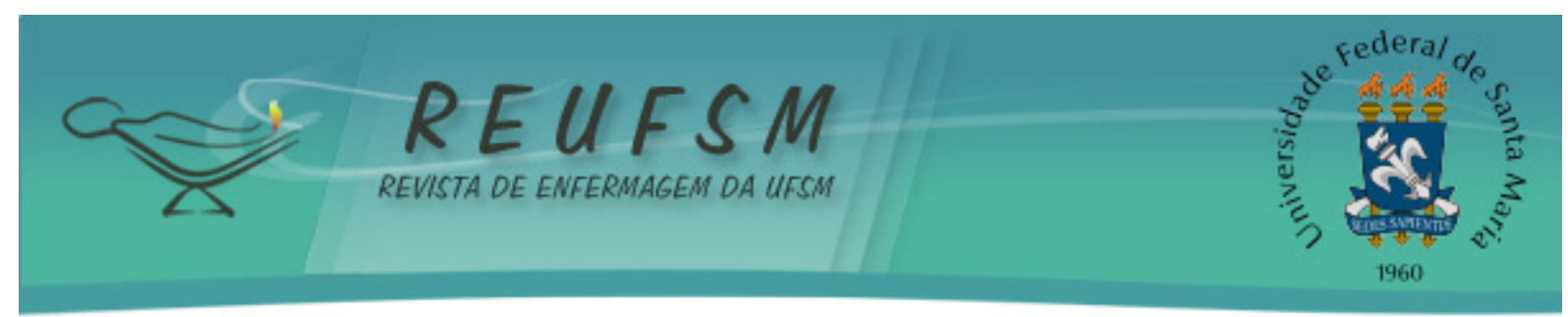

[...] Olha! Ele é um Ninja e ele luta com espada, e ele luta na escola. Ele vai no médico. E a mãe dele leva ele porque ele precisa, porque ele tem muitos problemas. [...] ele precisa, fazer atendimento porque ele tem depressão. Eles têm que cuidar porque ele tá depressivo, ele dá pancada, ele dá chute, ele dá porretada. E aí eles ficaram assim saco de pancada "tatatatata". (Amarelo)

[Como é que os médicos ajudam?]

[...] dando injeção pra acalmar os nervos. (Amarelo)

O relato de Amarelo apontou a percepção que tem de seu diagnóstico. Utiliza a fala egocêntrica ${ }^{25}$ imbuída de uma agressividade não mencionada na história original, o que confere o uso do mecanismo de defesa projeção, ou seja, quando o sujeito o identifica como externo ao mesmo tempo em que reconhece como seu próprio direito. ${ }^{2}$

A história 0 Menino Triste confere para Amarelo um espaço de expressão visto que o menino relata seus enfrentamentos familiares. Verbaliza seus problemas comportamentais, como a agressividade e a necessidade do tratamento em sua vida. Destaca-se que a agressividade é a principal queixa comportamental ligada ao sexo masculino em estudos com crianças e adolescentes em Centros de Atenção Psicossocial, chegando a $74 \%$, e a agitação como segunda queixa com $44 \%{ }^{27}$

Amarelo ainda citou a medicação em momentos de agitação psicomotora (crise), principalmente a medicação injetável, que o ajudava, segundo ele, a acalmar-se, relacionando o seu processo de saúde-doença com o serviço de saúde mental e os atendimentos psicológicos.

Considera-se que histórias elaboradas para trabalhar educação em saúde com crianças são estratégias eficazes que podem proporcionar maior adesão ao seu tratamento, assim como maior participação em sua terapêutica devido a uma maior compreensão do seu estado de saúde ${ }^{15}$, e reconhecimento emocional. ${ }^{17}$ Destaca-se, portanto, a importância das histórias como uma estratégia não medicamentosa que auxilia na percepção do processo de saúde e adoecimento. A criança, por meio de sua identificação, é favorecida a reconhecer-se, ou seja, externalizar o conhecimento sobre si própria e suas emoções.

Aponta-se ainda que espaços de tratamento em saúde que trabalham com contação de histórias têm percebido esta estratégia como facilitadora na realização de procedimentos médicos e de enfermagem, auxiliando a equipe de saúde na realização de suas atividades ${ }^{5-8,12,14}$, bem como na expressão de seus sentimentos. ${ }^{8,15,17}$

No segundo encontro, a etapa de reconstrução da narrativa deu-se com maior espontaneidade e familiaridade com o gravador, destacando-se as reações de Verde. Durante sua fala o menino mostrou-se muito afetivo, olhava para a boneca, segurando-a. Assim, ele contou o que estava acontecendo em sua vida e sua dificuldade em entender seus sentimentos. Azul aproveitou o momento para verbalizar suas dificuldades.

Eu tenho dificuldade [...] Eu não consigo fazer matemática de dezena. (Azul)

Eu sonhei que eu tinha um maninho pequeno [...] Eu dava carinho pra ele. [Verde aumentou a velocidade de sua fala] [...] Sabia? E o meu colega veio dá em mim, eu dei, um soco na cabeça. Ele me derrubou no chão, eu derrubei ele, eu subi em cima dele e dei um soco na cara dele. (Verde)

[E por que tu bateste nele?]

[...] Porque ele deu em mim e ele queria. (Verde)

[Como é que tu te sentiste?] 


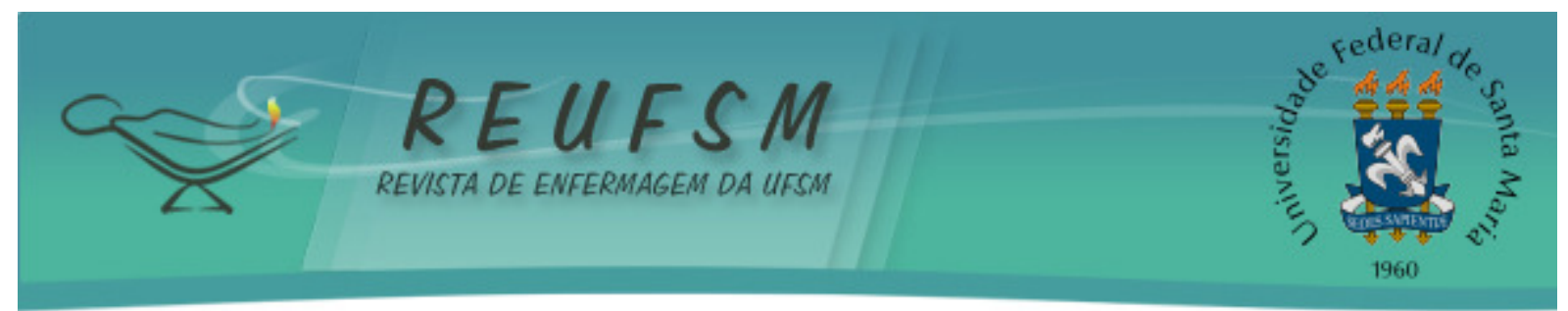

Bem, eu chorei. [...] Ele me chutou. (Verde)

Verde, quando relata seus sentimentos, trouxe que "sentiu-se bem e chorou". Há de se considerar dois aspectos: Verde pode ter dificuldades em diferenciar seus sentimentos, uma vez que a tristeza está dentre as emoções de difícil percepção pela criança. ${ }^{17}$ Contudo, as crianças tendem a identificar o choro como um momento de desabafo e alívio.

[E por que às vezes tu toma um remedinho aqui?]

Pra não fica agitado! (Verde)

[E o que é que tu faz quando tu fica agitado?]

Lalala... (Verde)

Novamente, os sentimentos referentes ao tratamento medicamentoso evidenciavam-se na relação terapêutica com o serviço. 0 uso da medicação aparece na fala infantil como ligado às inadequações comportamentais e à agressividade. A manifestação infantil com relação à suas vivências cotidianas também aparece em outros estudos. ${ }^{10,15,17}$

Verde não só verbalizou seus problemas como os demonstrou, por meio da sua agitação, atrapalhando a fala da menina Laranja, com sua canção "lalala". Verde manifestou-se novamente, relatando momentos de agressões que viveu em casa, seus sintomas de insegurança (ecoprese e enurese) ${ }^{* * * *}$, revelando seus sentimentos.

Ela estuda, ela tem que ter muita saúde. Ela tem que apanhar laço. Ela faz arte. Ela mexe nas minhas coisas e pega os negócios dos outros. E ela faz cocô e xixi na cama. (Verde)

[O que acontece quando a Lili toma laço?]

Ela mexe no mp3, e apanha, toma pau, e estraga. Porque ela fica mexendo nas coisas que não deve e, e não sabe obedecer. (Verde)

[E como ela se sente quando ela toma pau?]

Ela se sente chorando, fica com raiva. Deu! (Verde)

Compreende-se que a necessidade da criança narrar fatos reais é uma capacidade adquirida de separar-se da fantasia, pois revela a importância da história como um instrumento capaz de ajudar as crianças em seus processos psíquicos e constituírem seus pensamentos, assumindo a mesma importância de uma psicoterapia com crianças. ${ }^{1}$

Aponta-se, igualmente em outro estudo, que, mesmo existindo diferenças entre as histórias infantis clássicas e as histórias com temáticas específicas, estas são capazes de funcionar como objetos transicionais, estimulando as crianças a verbalizarem seus sentimentos. ${ }^{17}$ Constatou-se a importância das histórias-utilizadas, pois possibilitou a expressão de suas ansiedades na verbalização do diagnóstico em comum, refletindo a identificação-projetiva com as narrativas.

As crianças conseguiram expressar suas necessidades através da história recriada com demonstrações que as tornavam parte daquele contexto narrado em que a imaginação tornara-se conexão com o mundo externo. A reflexão oportunizada pela reconstrução da história revela o cotidiano vivenciado pela criança. Azul, Amarelo e Verde verbalizaram suas dificuldades com pesar expondo seus sentimentos enquanto Laranja falava dos sentimentos positivos com relação à escola.

${ }^{* * * *}$ Significam, respectivamente, defecar e urinar durante o sono, ou na roupa, quando acordado. 


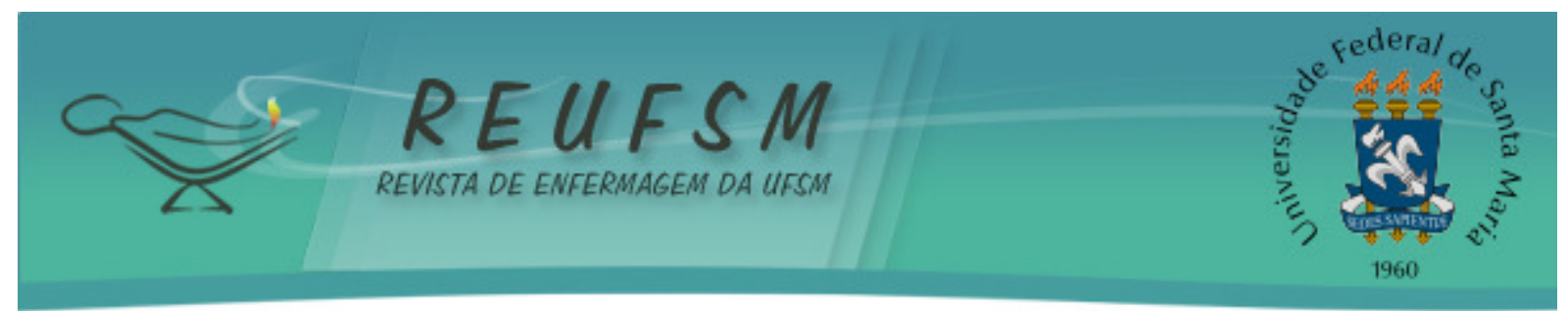

O grupo operativo possibilitou que os sentimentos fossem retrabalhados pelos indivíduos que formavam o grupo de forma que os aspectos manifestos e os aspectos implícitos puderam tornar-se conscientes. A oportunidade de trabalhar essas questões e verbalizar emoções acabou por tornar o grupo operativo não somente um espaço para a realização de tarefa explícita, mas um local que possibilitou a problematização de sentimentos, ${ }^{19}$ tornando-se um ambiente terapêutico em que se pode trabalhar com seus integrantes a reconstrução do processo saúde-doença, sendo um espaço de educação e de promoção em saúde mental.

Com o processo narrativo, pode-se perceber que ambas as histórias mostraram-se próprias para crianças, entre seis e dez anos, e de fácil entendimento para elas.

\section{CONSIDERAÇÕES FINAIS}

As crianças experienciaram suas emoções, de maneira individual e coletiva; tiveram momentos de identificação com as personagens com projeções significativas de seus sentimentos. Tal espaço proporcionado pelas histórias, bem como pelos instrumentos adicionais, funcionaram como mediadores às crianças no conhecimento sobre si próprias. A identificação-projeção infantil mostrou-se significativa.

As dificuldades de relacionamento e de aprendizagem puderam ser evidenciadas por meio das expressões das crianças durante a reconstrução das histórias. A raiva e as dificuldades comportamentais foram expressas. Com isso, as histórias utilizadas mostramse viáveis à escuta da vida das crianças e seus afetos.

Neste contexto, ao fazer uma reflexão sobre a forma de mediação estabelecida entre a pesquisadora e as crianças, percebe-se a importância da enfermagem intervir por meio de histórias, pois, durante o grupo operativo, verificou-se que as crianças absorveram o espaço terapêutico de forma mais prazerosa, podendo participar da construção de sua própria saúde, aprendendo, de forma lúdica, a se identificar e a reconhecer nos outros e em si mesmas pensamentos e sentimentos que auxiliam ou dificultam sua relação com os demais.

Contudo, a formação do profissional enfermeiro deve estar voltada à abordagem terapêutica, além de garantir que o processo de intervenção possa fazer parte da sua inserção em uma equipe multiprofissional de maneira a reforçar a atenção integral infantil no âmbito da interdisciplinaridade.

Considera-se que histórias infantis, elaboradas com base em possíveis vivências cotidianas das crianças, assumiram o papel de educar em saúde, assim como de promover a saúde mental, por meio da identificação direta das crianças com a problematização apresentada nas histórias. Assim, a contação de histórias pode ser entendida como uma ação de enfermagem alternativa e complementar ao tratamento das crianças com transtornos mentais.

No entanto, neste estudo, não foi possível avançar aos processos de ressignificação dos sentimentos infantis por se limitar a apenas dois encontros. Ademais, as histórias foram trabalhadas especificamente com crianças diagnosticadas e que frequentam um serviço especializado em saúde mental, não sendo possível verificar o impacto desses instrumentos no que tange a educação em saúde e a promoção de saúde mental em crianças não diagnosticas. Dessa forma, espera-se que esta pesquisa possa estimular os profissionais enfermeiros à intervenção lúdica por meio de histórias infantis com temáticas específicas para a saúde nos mais variados campos de atuação e de atenção à saúde da criança. 


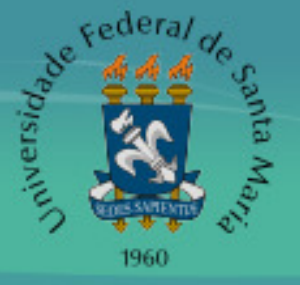

\section{REFERÊNCIAS}

1. Gutfreind C. Psicoterapia com crianças: benefícios do conto e da narratividade. Rev Bras Psicoter. 2004 set-dez;6(3):239-47.

2. Winnicott DW. O brincar e a realidade. Rio de Janeiro (RJ): Imago; 1975.

3. Giongo AL. Histórias para brincar. Correio da APPOA [Internet]. 2005 [acesso em 2009 ago20];136:36-48

Disponível

em:

http://www.appoa.com.br/uploads/arquivos/correio/correio136.pdf.

4. Schneider REF, Torossian SD. Contos de fadas: de sua origem à clínica contemporânea. Psicol Rev [Internet]. 2009 ago [acesso em 2013 jan 3];15(2):132-48. Disponível em: http://pepsic.bvsalud.org/pdf/per/v15n2/v15n2a09.pdf. Doi: $\quad$ 10.5752/P.16789563.2009V15N2P132.

5. Cintra SMP, Silva CV, Ribeiro CA. O ensino do brinquedo/brinquedo terapêutico nos cursos de Graduação em Enfermagem no Estado de São Paulo. Rev Bras Enferm [Internet]. 2006 jul-ago [acesso em 2013 dez 1];59(4):497-501. Disponível em: http://www.scielo.br/pdf/reben/v59n4/a05v59n4.pdf.

Doi:10.1590/S003471672006000400005.

6. Maia EBS, Ribeiro CA, Borba RIH. Compreendendo a sensibilização do enfermeiro para o uso do brinquedo terapêutico na prática assistencial à criança. Rev Esc Enferm USP [Internet]. 2011 [acesso em 2013dez 3];45(4): 839-46. Disponível em: http://www.scielo.br/pdf/reeusp/v45n4/v45n4a07.pdf . Doi: 10.1590/S008062342011000400007.

7. Francischinelli AGB, Almeida FA, Fernandes DMS. Uso rotineiro do brinquedo terapêutico na assistência a crianças hospitalizadas: percepção de enfermeiros. Acta Paul Enferm [Internet]. 2012 [acesso em 2013 dez 3];25(1):18-23. Disponível em: http://www.scielo.br/pdf/ape/v25n1/v25n1a04.pdf . Doi: 10.1590/S0103-210020 12000100004.

8. Ceribelli C, Nascimento LC, Pacifico SMR, Lima RAG. A mediação de leitura como recurso de comunicação com crianças hospitalizadas. Rev Latinoam Enferm [Internet]. 2009 [acesso em 2013 dez 3];17(1):81-7. Disponível em: http://www.scielo.br/pdf/rlae/v17n1/pt_13.pdf. Doi: 10.1590/S0104-11692009000100013.

9. Jansen MF, Santos RM, Favero L. Benefícios da utilização do brinquedo durante o cuidado de enfermagem prestado à criança hospitalizada. Rev Gaúcha Enferm [Internet]. 2010 jun [acesso em 2013 dez 3];31(2):247-53. Disponível em: http://www.scielo.br/pdf/rgenf/v31n2/07.pdf. Doi:10.1590/S1983-4472010000200007.

10. Giacomello KJ, Melo LL. Do faz de conta à realidade: compreendendo o brincar de crianças institucionalizadas vítimas de violência por meio do brinquedo terapêutico. Ciênc Saúde Coletiva [Internet]. 2011 [acesso em 2013 dez 3];16(Supl 1):1571-80. Disponível em: http://www.scielo.br/pdf/csc/v16s1/a93v16s1.pdf. 81232011000700093.

11. Lemos LMD, Pereiral WJ, Andrade JS, Andrade ASA. Vamos cuidar com brinquedos? Rev Bras Enferm [Internet]. 2010 [acesso em 2013 dez 3];63(6):950-5. Disponível em: http://www.scielo.br/pdf/reben/v63n6/13.pdf. Doi: 10.1590/S0034-71672010000600013.

12. Garcia NR, Pfeifer LI, Panúncio-Pinto MP. As caixas de histórias na visão de profissionais de saúde como estratégia de enfrentamento da hospitalização infantil. Rev Ter Ocup Univ [Internet]. 2012 maio/ago [acesso em 2013 dez 3]; 23(2):169-77. Disponível 


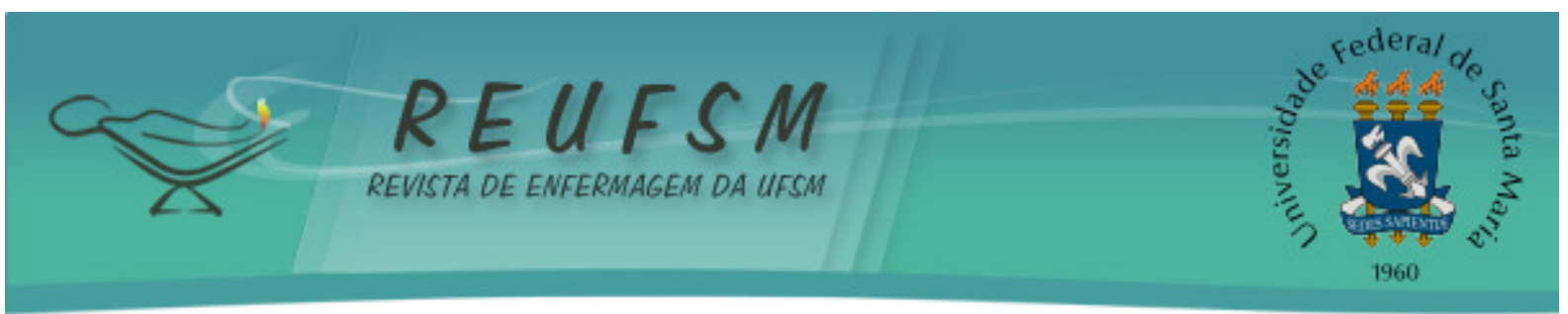

em: http://www.revistas.usp.br/rto/article/view/49073/53146. Doi: 10.11606/issn.22386149.v23i2p169-177.

13. Medeiros G, Matsumoto S, Ribeiro CA, Borba RI. Brinquedo terapêutico no prepare da criança para punção venosa em pronto socorro. Acta Paul Enferm [Internet]. 2009 [acesso em 2013 dez 3];22(N Esp):909-15. Disponível em: http://www.scielo.br/pdf/ape/v22nspe/13.pdf. Doi: 10.1590/S0103-21002009000700013.

14. Paladino CM, Carvalho R, Almeida FA. Therapeutic play in preparing for surgery: behavior of preschool children during the perioperative period. Rev Esc Enferm USP [Internet]. 2014 [acesso em 2013 dez 3];48(3):423-9. Disponível em: http://www.scielo.br/pdf/reeusp/v48n3/0080-6234-reeusp-48-03-423.pdf. 10.1590/S0080-623420140000300006.

15 Brondani JP, Pedro ENR. A história infantil como recurso na compreensão do processo saúde-doença pela criança com HIV. Rev Gaúcha Enferm [Internet]. 2013 [acesso em 2015 fev 26];34(1):14-21. Disponível em: http: / / www.scielo.br/scielo.php?script=sci_pdf\&pid=S1983$14472013000100002 \& \operatorname{lng}=e n \& n r m=i s o \& t \operatorname{lng}=$ pt. Doi: $10.1590 /$ S1983-14472013000100002.

16. Sposito AMP, Sparapani VC, Pfeifer LI, Lima RAG, Lucila Castanheira Nascimento LC. Estratégias lúdicas de coleta de dados com crianças com câncer: revisão integrativa. Rev Gaúcha Enferm [Internet]. 2013[acesso em 2015 fev 26];34(3):187-95. Disponível em: http://www.scielo.br/pdf/rgenf/v34n3/a24v34n3.pdf. Doi: 10.1590/S198314472013000300024.

17. Braga GC, Silveira EM, Coimbra VCC, Porto AR. Promoção em saúde mental: a enfermagem criando e intervindo com histórias infantis. Rev Gaúcha Enferm [Internet]. 2011 mar [acesso em 2013 dez 3];32(1):121-8. Disponível em: http://www.scielo.br/pdf/rgenf/v32n1/a16v32n1.pdf. Doi: 10.1590/S198314472011000100016.

18. Minayo MCS. O desafio do conhecimento: pesquisa qualitativa em saúde. $12^{\mathrm{a}}$ ed. São Paulo: Hucitec; 2010.

19. Pichon-Rivière E. O processo grupal. $8^{\mathrm{a}}$ ed. Porto Alegre: Martins Fontes; 2009.

20. Braga GC, Brondani JP. O Menino triste. $1^{\text {a }}$ ed. Pelotas: Editora e Gráfica Universitária PREC-UFPel; 2007.

21. Brondani JP, Braga GC. Lili a boneca de corda. $1^{\text {a }}$ ed. Porto Alegre: Novo Tempo; 2014.

22. Pillar AD. Desenho e escrita como sistemas de representação. $2^{\mathrm{a}}$ ed. Porto Alegre: Penso; 2012.

23. Brasil. Ministério da Saúde. Conselho Nacional de Saúde. Resolução CNS n¹96, de 10 de outubro de 1996. Diretrizes e normas regulamentadoras de pesquisa envolvendo seres humanos. Brasília (DF): Ministério da Saúde; 1996.

24. Rocha EAC. Por que ouvir as crianças? Algumas questões para um debate científico multidisciplinar. In: Cruz SHV, organizador. A criança fala: a escuta de crianças em pesquisas. São Paulo: Cortez; 2008.

25. Vigotski LS. A formação social da mente: o desenvolvimento dos processos psicológicos superiores. $7^{\mathrm{a}}$ ed. São Paulo: Martins Fontes; 2007. 


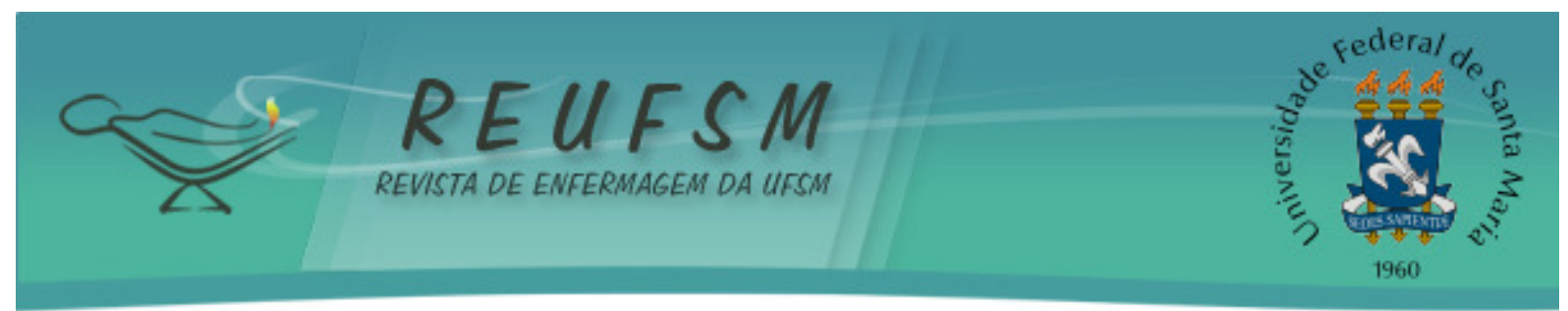

26. Castro MGK. Reflexões acerca da prática da psicoterapia com crianças: uma ponte entre passado, presente e futuro. Rev Bras Psicoter. 2004;6(3):301-16.

27. Arrué AM, Neves ET, Terra MG, Magnago TSBS, Jantsch LB, Pieszak GM, et al. Crianças/adolescentes com necessidades especiais de saúde em centro de atenção psicossocial. Rev Enferm UFSM [Internet]. 2013 jan/abr [acesso em 2014 jan 22];3(2):22737. Disponível em: http://cascavel.ufsm.br/revistas/ojs2.2.2/index.php/reufsm/article/view/7827/pdf. Doi: 10.5902/217976927827.

Data de recebimento: $01 / 07 / 2014$

Data de aceite: 30/04/2015

Contato do autor responsável: Gimene Cardozo Braga

Endereço postal: Rua Bento Munhoz da Rocha Neto s/n, Centro, Palmas, CEP: 85555-000

E-mail: gimene.braga@ifpr.edu.br 